\title{
Indo-French High-resolution Thermal Infrared Space Mission for Earth Natural Resources Assessment and Monitoring - Concept and Definition of TRISHNA
}

\begin{abstract}
J.-P. Lagouarde ${ }^{1 *}$, Bimal K. Bhattacharya ${ }^{2}$, P. Crébassol ${ }^{3}$, P. Gamet ${ }^{3}$, Dheeraj Adlakha ${ }^{2}$, C.S. Murthy ${ }^{4}$, S. K. Singh ${ }^{2}$, Manoj Mishra $^{2}$, Rahul Nigam ${ }^{2}$, P. V. Raju ${ }^{4}$, S. S. Babu ${ }^{5}$, M.V. Shukla ${ }^{2}$, M. R. Pandya ${ }^{2}$, G. Boulet ${ }^{6}$, X. Briottet ${ }^{7}$,I. Dadou ${ }^{8}$, G. Dedieu ${ }^{9}$, M. Gouhier ${ }^{10}$, O. Hagolle ${ }^{9}$, M. Irvine ${ }^{1}$, F. Jacob ${ }^{11}$, K. K. Kumar ${ }^{5}$, B. Laignel ${ }^{13}$, P. Maisongrande ${ }^{3}$, K. Mallick ${ }^{14}$ A. Olioso ${ }^{15}$, C. Ottlé16, J.-L. Roujean ${ }^{9}$, J. Sobrino ${ }^{18}$, R. Ramakrishnan ${ }^{2}$, M. Sekhar ${ }^{19}$, S. S. Sarkar ${ }^{2}$
\end{abstract}

\author{
1. INRA, UMR 1391 ISPA, F-33140 Villenave d'Ornon, France \\ 2. ISRO, Space Applications Centre, Ahmedabad 380015, India \\ 3. CNES, 18 av. Edouard Belin, F-31401 Toulouse, France \\ ${ }^{4}$ ISRO, NRSC, National Remote Sensing Centre, Hyderabad 500 037, India \\ 5. ISRO, Space Physics Laboratory, Thiruvananthapuram 695 022, India \\ 6. IRD, UMR 5126 CESBIO,F-31401 Toulouse, France \\ 7. ONERA, DOTA, 2 av. Edouard Belin, F-31055 Toulouse, France \\ 8. LEGOS, 18 av. Edouard Belin, F-31401 Toulouse, France \\ 9. CESBIO, Université de Toulouse, UMR 5126 CESBIO,F-31401 Toulouse, France \\ 10. OPGC, LMV, Université Clermont Auvergne, Clermont-Ferrand, France \\ 11. IRD, UMR 1221 LISAH, 2 place Viala, F-34060 Montpellier, France \\ 13. Université de Rouen, UMR 6143 M2C, F-76821 Mont Saint Aignan, France \\ 14. LIST, ERIN, 41, rue du Brill, L-4422 Belvaux, Luxembourg \\ 15. INRA, UMR 1114 EMMAH, F-84000 Avignon, France \\ 16. LSCE, UMR 8212, Centre d'Etudes de Saclay, F-91191 Gif-sur-Yvette, France \\ 18. Universitat de Valencia, UCG/IPL, Parque Científico, E-46980 Paterna, Spain \\ 19. IISc, CV Raman Rd, Bengaluru, Karnataka 560 012, India
}

\section{Commission III, WG III/10}

KEY WORDS: TIR remote sensing, surface energy balance, TRISHNA mission, global monitoring

\section{ABSTRACT:}

The Indian and French Space Agencies, ISRO and CNES, have conceptualized a space-borne Thermal Infrared Reflectance (TIR) mission, TRISHNA (Thermal infRared Imaging Satellite for High-resolution Natural Resource Assessment). The primary design drivers of TRISHNA are the monitoring of (i) terrestrial water stress and use, and of (ii) coastal and continental water. A suit of four TIR bands and six optical bands is planned. The TIR bands will be centred at $8.6 \mu \mathrm{m}, 9.1 \mu \mathrm{m}, 10.3 \mu \mathrm{m}$ and $11.5 \mu \mathrm{m}$ to provide noonnight global observations at $57 \mathrm{~m}$ nadir resolution over land and coastal regions. The field of view (FOV) is $\pm 34^{\circ}$ and the orbit of 761 $\mathrm{km}$ altitude was designed to allow 3 sub-cycle acquisitions during the 8- day cycle. The optical bands correspond to blue, green, red, and NIR plus two SWIR bands at $1.38 \mu \mathrm{m}$ and $1.61 \mu \mathrm{m}$. The green, red, NIR and the $1.61 \mu \mathrm{m}$ SWIR bands will have better radiometry quality than those of AWiFS. ISRO and CNES will develop optical and TIR payloads, respectively. Assessing evapotranspiration and furthermore Gross and Net Primary Productivity (GPP and NPP) will in turn assist in quantifying water use in rainfed and irrigated agriculture, water stress and water use efficiency, with expected applications to agricultural drought and early warning, crop yield prediction, water allocation, implementation of water rights, crop insurance business and agro-advisories to farmers. The other scientific objectives of TRISHNA are also briefly described. TRISHNA instrument will fly aboard a ISRO spacecraft scheduled to be launched from 2024 for a minimum period of 5 years' mission lifetime.

\footnotetext{
${ }^{*}$ Corresponding author. Email : jean-pierre.lagouarde@inra.fr
} 


\section{INTRODUCTION}

Surface temperature and its day-night contrast over land is the fundamental variable to characterize evapotranspiration from vegetation, lake evaporation, snow melt, urban heat islands and presence of fresh water in turbid coastal fringes, among others. Accurate quantification of surface emissivity helps in improving the accuracy of retrieving land surface temperature (LST) from thermal remote sensing signatures. Satellite thermal remote sensing has been recognized as the only viable means to generate consistent and systematic records of surface temperature at various space-time scales. Landsat- 8 having split thermal infrared (TIR) bands and ASTER with multiple thermal bands within $8-12 \mu \mathrm{m}$ provide thermal remote sensing observations at a high spatial resolution varying from $90-100 \mathrm{~m}$ with satellite overpass time around 10:30 to 11:30 hrs, but with 16-day revisit only. Earlier studies over India, France and elsewhere suggested that evapotranspiration is better estimated using noon-time TIR observations between 12:00 - 14:00 hrs. For time being MODIS AQUA and TERRA provide TIR observations with a time shift of 2 hours on either side of noon and at $1 \mathrm{~km}$ spatial resolution. NASA is planning to develop the HysPIRI (Hyperspectral Infrared Imager) mission combining optical hyperspectral and thermal sensors to derive accurate quantification of surface temperature and emissivity. As a precursor to that, a prototype instrument called, ECOSTRESS (ECOsystem spaceborne Thermal Radiometer Experiment on Space Station), is placed aboard the International Space Station (ISS) with five TIR bands and one SWIR band at $1.6 \mu \mathrm{m}$ to provide observations at $74 \mathrm{~m}$ but for only one year. Currently, no polar orbiting satellite mission is providing high resolution spatio-temporal data such as better than $60 \mathrm{~m}$ with 3-8 day revisit cycle and a global coverage for a simultaneous estimate of LST/SST and land surface emissivity.

\section{RELEVANCE TO GLOBAL AGRICULTURAL MONITORING}

The use of satellite-based earth observation data for globalscale agricultural monitoring is limited primarily to optical remote sensing observations or its derived products in the form of vegetation indices or Leaf Area Index (LAI) / FAPAR (Fraction Absorbed Photosynthetically Active Radiation) retrieved from Canopy Radiative Transfer (CRT) model. Time series data of high resolution multispectral optical remote sensing has been proved to be ideal for crop discrimination especially in those regions or crop growing seasons less covered by cloud presence and persistence. However, it carries less information manifested from physical or physiological growth processes such as transpiration, soil evaporation, photosynthesis and respiration. Surface temperature acts as fundamental coupler between surface energy balance and plant growth processes. Magnitude of vertical gradients resulted from differences among surface radiometric temperature, aerodynamic temperature, air temperature in soil-canopy cover complex get modulated based on water supply to soil and root system ultimately influence crop-water relations and simultaneous uptake of water and nutrients. Therefore, High-resolution high-repeat thermal remote sensing observations will serve as key data sources for implementing policy implementation related to water rights and water allocation in agriculture, deriving digital global agricultural water footprint in terms of green and blue water use for virtual water trading, early warning for agricultural drought at three stages (early, middle and terminal) as well as crop yield prediction at finer scale to settle yield dispute resolution for crop insurers. Through different countries have been using thermal infrared remote sensing observations from geostationary platform primarily for agricultural drought assessment these did not have global coverage and could not provide thermal IR observations at a scale better than $100 \mathrm{~m}$. Therefore, a global high-resolution high-repeat thermal IR mission is ideal for improved crop assessment and water management.

\section{RESEARCH OVERVIEW OF THERMAL REMOTE SENSING FOR AGRICULTURE}

Generally Single-Source and Dual-Source Surface energy balance modelling approaches are used to estimate ET using thermal IR sensing data. Over the recent years, various ET models have been developed that used remote sensing and ancillary surface and ground-based observations. Till date, several energy balance algorithms are available for calculating ET through remote sensing such as SEBAL (Bastiaanssen et.al.1998) and SEBS (Su, 2002). They are single-source model which considers soil and plant as single source. In addition to this, there is dual-source or two-source (soil and vegetation canopy) model, e.g. TSEB (Norman \& Becker 1995), SEBI (Menenti and Choudhury 1993) and ALEXI (Anderson et al. 1997). Both parametric and nonparametric modelling structures are being used within the energy balance framework to estimate ET. In the Indian subtropics, a set of studies related to ET monitoring from satellite-based thermal remote sensing have been reported primarily using parametric modelling structures during 2007 to 2010. There are set of studies (e.g. Mallick et al., 2009, Bhattacharya et al., 2010, Eswar et al., 2017a, 2017b) that demonstrated the potential of satellite-based thermal infrared and optical remote sensing datasets for the estimation of ET at regional scales, to estimate consumptive water use and crop yield prediction (Mallick et al., 2009). Similarly, in France, EVapotranspiration Assessment from SPAce (EVASPA) (Gallego-Elvira et al. 2013) and Soil Plant Atmosphere and Remote Sensing Evapotranspiration (SPARSE) (Boulet et al. 2015) models have been developed and are being evaluated for large-scale ET estimation and for agricultural applications. The EVASPA platform brings several algorithms all together to provide an ensemble simulation with the uncertainty on final ET products (Gallego-Elvira et al, 2013). Large number of global ET products have been derived in recent years, including remote sensing-based products using multiple approaches. However, these products are available at coarse spatial resolution (such as $0.25^{\circ} \times 0.25^{\circ}$ ) or lower temporal resolution (monthly). The only ET product that is currently available at high spatial $(500 \mathrm{~m})$ and reasonable temporal (8 days) resolution is the MODIS 16 ET product (Mu et al., 2011). However, McCabe et al. (2016) mentioned that the reduced performance of the MODIS ET product may be due to the underlying structural and parameterization issues in model formulation, which 
requires further investigation. These results raise questions about the reliability of the MODIS ET product over India.In addition, MOD16ET product does not use any thermal remote sensing observations. Thus there is a need for reliable, continuous, high resolution ET dataset over Indian subtropics from satellite-based thermal remote sensing. To cope with the lack of LST data for cloudy days, research efforts are devoted to temporal gap-filling between discrete ET estimations. Significant progress is expected from alternative efficient supports, such as surface humidity or meteorological models outputs for instance, to replace evaporative fraction or stress index classically used up to now.

\section{TRISHNA MISSION CONCEPT AND DEFINITION}

Indo-French high-resolution space-borne TIR mission named as TRISHNA (Thermal infrared Imaging Satellite for Highresolution Natural resource Assessment) has been conceptualized considering the global needs and possibility of fusion of strength of both the space agencies. Indian Space Research Organization (ISRO) had successfully developed Resourcesat series of polar orabiting satellites such as Resourcesat -1,2 and 2A with three-tier imaging systems with few multi-spectral bands at a varying spatial resolutions such as $5.4 \mathrm{~m}, 23.5 \mathrm{~m}, 56 \mathrm{~m}$ from LISS IV, LISS III, AWiFS sensors, respectively having 45-day, 25-day and 5-day repeativity or revisit. However, Resourcesat does not have any TIR band. In the past years, the French space agency, CNES, carried out several projects of high spatio-temporal TIR mission, such as MISTIGRI or THIRSTY (in cooperation with NASA/JPL). The primary design drivers of TRISHNA mission are (1) Terrestrial Ecosystem Stress and Water Use and (2) Inland and coastal processes for better assessment of sub-mesoscale activities. The secondary design drivers are Urban micro-climate (e.g. Urban Heat Island), solid earth (e.g. Coal or peat fires, geothermal exploration), cryosphere (e.g. Snow melt runoff) and atmospheric characterization.

The summary of the baseline requirements for TRISHNA are as follows:

- Resolution: $50 \mathrm{~m}$ at nadir ( $<100 \mathrm{~m}$ edges of swath). Binned at $1000 \mathrm{~m}$ over oceans.

- Revisit and coverage: 3 observations for any ground location per 8 days period (from the 3 subcycles of a 8 day-orbit at $761 \mathrm{~km}$ ), global coverage.

- NeDT: $0.3 \mathrm{~K}(0.1 \mathrm{~K}$ for ocean binned at $1 \mathrm{~km})$ and saturation temperature $400 \mathrm{~K}$

Spectral bands

- $\quad$ TIR: $8.6 \mu \mathrm{m}, 9.1 \mu \mathrm{m}, 10.3 \mu \mathrm{m}$ and $11.5 \mu \mathrm{m}$

- VNIR: $0.485,0.555,0.650$ and $0.860 \mu \mathrm{m}$

- $\quad$ SWIR: $1.650 \mu \mathrm{m}$ and $1.38 \mu \mathrm{m}$.

- Possible degradation of the spatial resolution for blue $(0.485 \mu \mathrm{m})$ and cirrus $(1.38 \mu \mathrm{m})$ bands.

It is decided that ISRO will develop VNIR-SWIR payloads and CNES will develop TIR payload. TRISHNA will be launched by ISRO spacecraft.

\section{JUSTIFICATION FOR TRISHNA SPECIFICATIONS}

The highest possible revisit period would be desirable in order (i) to cope with the limitations of data availability due to clouds and (ii) to minimize the impact of uncertainty in LST due to atmospheric turbulence on the accuracy of final ET and water budget products. However, the requirement of global coverage severely constrains the swath angle for a single satellite mission. It results that only a 3 day-revisit can be achieved with a reasonable scan angle lower than $35^{\circ}$. An analysis of the size of fields in a typical agricultural landscape in the South West of France led us to recommend a resolution close to $50 \mathrm{~m}$, corresponding to about a hundred meters at the swath edges. In many places of India, the very fragmented landscape makes $50 \mathrm{~m}$ at least mandatory (Eswar et al, 2016). However, at lower resolution, the atmospheric turbulence may induce a too significant uncertainty on LST. Technical constraints are also to be considered. In particular, the size of existing/under development detectors is still a technical limitation against the swath. The final trade-off is a $57 \mathrm{~m}$ spatial resolution at nadir.

Four reasons led us to recommend a $1 \mathrm{pm}$ overpass time. (1) According to models, it provides the best accuracy on ET retrievals (Delogu et al, 2012). (2) The lower sensitivity of time (d(LST)/dt close to $0{ }^{\circ} \mathrm{C} /$ hour at that moment) facilitates the combination with surface or meteorological models which have time steps of around half-an-hour. For comparison, around 10:00 (solar time), the variation of LST is about 4 ${ }^{\circ} \mathrm{C} /$ hour. (3) The corresponding night overpass around $1 \mathrm{am}$ is best adapted to measurements over water bodies because late enough to remove possible thermal inertia effects. (4) For mid latitudes, the directional anisotropy error on LST is reduced because the hot spot is situated in a plane perpendicular to the scan line (Duffour et al, 2016).

A detailed analysis of the 3-day orbit at $666 \mathrm{~km}$ selected for THIRSTY (Lagouarde et al, 2013) revealed it was not suited for the inter-tropical zone in which data may be affected by hot-spot during several months per year (Duffour et al, 2016). As no robust model close to the hot-spot peak is available today to correct LST data, an alternative orbit with a 8-day revisit $(761 \mathrm{~km})$ was retained. Its $3 / 2 / 3$ sub-cycles could provide at least 2 hot-spot free data out of 3 in the intertropical zone.

In the TIR, two bands centered on $10.3 \mu \mathrm{m}$ and $11.5 \mu \mathrm{m}$ have been selected to apply the split-window method. Two bands centered at 8.6 and $9.1 \mu \mathrm{m}$ are added to perform the temperature - emissivity separation using the TES method (Jacob et al, 2017). The exact shape of TIR spectral filters is currently being studied using an end-to-end simulator. Moreover, a study has been conducted to demonstrate that it is mandatory to embark both TIR and VNIR/SWIR instruments on the same platform. In the VNIR domain, the vegetation bands at 0.650 and $0.860 \mu \mathrm{m}$ are mandatory. A blue band $(0.485 \mu \mathrm{m})$ with a cirrus band $(1.38 \mu \mathrm{m})$ both acquired at lower resolution $(100-200 \mathrm{~m})$ are required for cloud discrimination. A green band $(0.555 \mu \mathrm{m})$ is devoted to coastal applications and snow discrimination. Finally, a 1.650 
$\mu \mathrm{m}$ SWIR band is added to address aerosol characterization and albedo estimation particularly.

The blue and $1.38 \mu \mathrm{m}$ SWIR bands will be used for cloud detection. Aerosol characterized from blue and 1.61 SWIR bands, atmospheric water vapour extractable from splitwindow TIR bands (at 10.3 and $11.5 \mu \mathrm{m}$ ) and the atmospheric ozone content from $9.1 \mu \mathrm{m}$ TIR band will help to determine accurate surface reflectance. Green, red, NIR and SWIR bands will be used to retrieve surface albedo, vegetation index/ vegetation fraction, LAI/fAPAR, water Chlorophyll and water turbidity products. Accurate LST and surface emissivity will be retrieved from the four TIR bands. All these products will be used in surface energy balance and productivity models to estimate global-scale evapotranspiration and vegetation primary productivity

\section{CONCLUSIONS}

TRISHNA is currently in 'A' phase (feasibility assessment) till end 2019. It will be followed by a one-year B phase. The launch could be foreseen from 2024. The mission will have minimum life-span of 5 years. TRISHNA remains very original in the international context of the high spatiotemporal TIR and to fulfil the need of improved global agricultural monitoring.

\section{ACKNOWLEDGEMENTS}

The authors are thankful to Director, Space Applications Centre and Chairman, Indian Space Research Organization for encouraging to define this science mission. This work is supported by the 'Centre National d'Etudes Spatiales' (CNES) through the TOSCA group (Terre, Océan, Surfaces Continentals, Atmosphere).

\section{REFERENCES}

Anderson, M., Norman, J., Diak, G., Kustas, W., \& Mecikalski, J. (1997), A two-source time-integrated model for estimating surface fluxes from thermal infrared satellite observations. Remote Sensing of Environment, 60,pp. $195-$ 216.

Bastiaanssen, W. G. M., Noordman, E. J. M., Pelgrum, H., Davids, G., Thoreson, B. P., and Allen, R. G. (2005), SEBAL model with remotely sensed data to improve water-resources management under actual field conditions. Journal of Irrigation and Drainage Engineering, 131(1), pp. 85-93. [doi:10.1061/(ASCE)0733- 9437(2005)131:1(85)]

Bhattacharya, B.K., Mallick, K., Patel, N.K. and Parihar, J.S. (2010), Regional clear sky evapotranspiration over agricultural land using remote sensing data from Indian geostationary meteorological satellite, Journal of Hydrology, 387, pp. 65-80, doi: 10.1016/j.jhydrol.2010.03.030

Bhattacharya, B.K., Mallick, K., Patel, N.K. and Parihar, J.S. (2010), Regional clear sky evapotranspiration over agricultural land using remote sensing data from Indian geostationary meteorological satellite, J. Hydrol., 387, pp. $65-80$.
Boulet, G., Mougenot, B., Lhomme, J.-P., Fanise, P., LiliChabaane, Z., Olioso, A., Bahir, M., Rivalland, V., Jarlan, L., Merlin, O., Coudert, B., Er-Raki, S., and Lagouarde, J.-P.: The SPARSE model for the prediction of water stress and evapotranspiration components from thermal infra-red data and its evaluation over irrigated and rainfed wheat, Hydrol. Earth Syst. Sci., 19, pp. 4653-4672, https://doi.org/10.5194/hess-19-4653-2015, 2015.

Delogu, E., Boulet, G., Olioso, A., Coudert, B., Chirouze, J., E. Ceschia, E., Dantec, V.L., Marloie, O., Chehbouni, G. and Lagouarde, J. P. 2012. Reconstruction of temporal variations of evapotranspiration using instantaneous estimates at the time of satellite overpass. Hydrology and Earth System Sciences, 16, pp. 2995-3010. doi:10.5194/hess-16-29952012

Duffour, C., Lagouarde., J.-P., and Roujean, J.-L.(2016), A two parameter model to simulate thermal infrared directional effects for remote sensing applications. Rem. Sens. Environ. 186 pp. $250-261$.

Eswar, R., Sekhar M., Bhattacharya, B.K. (2013), A simple model for spatial disaggregation of evaporative fraction: comparative study with thermal sharpened land surface temperature data over India. J. of Geophys. Research: Atmospheres, 118 (21): pp. 12,029-12,044.

Eswar, R., Sekhar M., Bhattacharya, B.K. (2017), Comparison of three remote sensing based models for the estimation of latent heat flux over India, Hydrological Sciences Journal, 62:16, pp. 2705-2719, DOI: $10.1080 / 02626667.2017 .1404067$

Eswar, R., Sekhar M., Bhattacharya, B.K. (2017b), Comparison of three remote sensing based models for the estimation of latent heat flux over India, Hydrological Sciences Journal, 62(16), pp. 2705-2719, doi: $10.1080 / 02626667.2017 .1404067$

Eswar, R., Sekhar M., Bhattacharya, B.K. and Bandyopadhyay, S. (2017a), Spatial disaggregation of latent heat flux using contextual models over India, Remote Sensing, 9, pp. 949, doi: 10.3390/rs9090949

Gallego-Elvira, B., Olioso, A., Mira, M., et al., (2013), “ EVASPA (Evapotranspiration Assessment from Space) Tool; An overview", Procedia Environmental Sciences, vol.19,pp.303-310

Gallego-Elvira, B., Olioso, A., Mira, M., Reyes-Castillo, S., Boulet, G., Marloie, O., Garrigues, S., Courault, D., Weiss, M., Chauvelon, P. and Boutron, O.(2013), EVASPA (EVapotranspiration Assessment from SPAce) tool: An overview. Procedia Environmental Sciences, 19, pp. 303310 .

Jacob, F., Lesaignoux, A., Olioso, A., Weiss, M., Caillault, Jacquemoud, S., Nerry, F., French, A., Schmugge, T., Briottet, X., Lagouarde, J.-P. (2017), Reassessment of the temperature - emissivity separation from multispectral thermal infrared data: Introducing the impact of vegetation canopy by simulating the cavity effect with the SAILThermique model. Remote Sens. of Environ., 198: pp. 160172 
Lagouarde, J.-P., Bach, M., Sobrino, J.A., Boulet, G., Briottet, X., Cherchali, S., Coudert, B., Dadou, I., Dedieu, G., Gamet, P., Hagolle, O., Jacob, F., Nerry, F., Olioso, A., Ottlé, C., Roujean, J.-L. and Fargant, G.(2013), The MISTIGRI Thermal Infrared project: scientific objectives and mission specifications. Int. J. Remote Sens., 34 (9-10), pp. 34373466.

Mallick, K., Bhattacharya, B.K., Rao, V.U.M., Reddy, D.R., Banerjee, S., Venkatesh, H. , Pandey, V. , Kar, G. , Mukherjee, J., Vyas, S.P., Gadgil, A.S. and Patel, N.K.(2009), Latent heat flux estimation in clear sky days over Indian agroecosystems using noontime satellite remote sensing data. Agric. For. Meteorol. 149 pp. 1646-1665.

McCabe, M.F., Ershadi, A., Jimenez, C., Miralles, D.G., Michel, D. and Wood, E.F. (2016), The GEWEX LandFlux project: evaluation of model evaporation using tower-based and globally gridded forcing data, Geoscientific Model Development, 9, pp. 283-305, doi:10.5194/gmd-9-283-2016.
Menenti, Massimo \& J. CHOUDHURY, B. (1993), Parameterization of land surface evaporation by means of location dependent potential evaporation and surface temperature range. Proceedings of IAHS Conference on Land Surface Processes.

$\mathrm{Mu}$, Q., Zhao, M. and Running, S.W. (2011), Improvements to a MODIS global terrestrial evapotranspiration algorithm, Remote Sensing of Environment, 115, pp. 1785-1800.

Norman, J.M., \&Becker, F. (1995), Terminology in thermal infrared remote sensing of natural surface, Agricultural and Forest Meteorology,77(3-4),pp. 153-166.

Seguin, B., Assad, E., Freaud, J. P., Imbernon, J. P., Kerr, Y., \& Lagouarde, J. P. (1989), Use of meteorological satellite for rainfall and evaporation monitoring. International Journal of Remote Sensing, 10, pp. 1001-10 